\title{
Meios de cultura, reguladores de crescimento e fontes de nitrogênio na regulação da calogênese do pau-brasil (Caesalpinia echinata Lam.)
}

\author{
Elias Terra Werner ${ }^{1}$, Camilla Rozindo Dias Milanez ${ }^{1}$, Liana Holda Golin Mengarda ${ }^{1}$, \\ Wagner Aparecido Vendrame ${ }^{2}$ e Geraldo Rogério Faustini Cuzzuol ${ }^{1,3}$
}

Recebido em 25/11/2009. Aceito em 19/10/2010

\begin{abstract}
RESUMO - (Meios de cultura, reguladores de crescimento e fontes de nitrogênio na regulação da calogênese do pau-brasil (Caesalpinia echinata Lam.)). A regulação da calogênese é o primeiro passo para a embriogênese somática indireta in vitro. Nesse sentido, foram investigados os efeitos de diferentes meios de cultura, reguladores de crescimento e fontes nitrogenadas no desenvolvimento de calos em tecidos foliares de Caesalpinia echinata (pau-brasil). Explantes foliares foram cultivados em meios de cultura MS, B5, White e WPM. Testou-se, também, o efeito dos compostos nitrogenados $\left(\mathrm{NH}_{4} \mathrm{NO}_{3} \mathrm{KNO}_{3}\right.$ e glutamina) e a interação entre auxinas (2,4-D, AIA e AIB) e citocininas (BAP e KIN) na desdiferenciação celular indicado pela formação de calos. Os meios MS, B5 e White não foram significantemente diferentes e proporcionaram melhores resultados. Em meio MS contendo as fontes nitrogenadas $2,4 \mathrm{~g}$ $\mathrm{L}^{-1} \mathrm{NH}_{4} \mathrm{NO}_{3}$ e $1,35 \mathrm{~g} \mathrm{~L}^{-1}$ glutamina $+4,11 \mathrm{~g} \mathrm{~L}^{-1}$ de $\mathrm{KNO}_{3}$ na presença de $1,0 \mathrm{mg} \mathrm{L}^{-1}$ 2,4-D e 5,0 $\mathrm{mg} \mathrm{L}^{-1}$ BAP ocorreu maior proliferação celular indicada pela massa fresca dos calos. As combinações dos reguladores $0,5 \mathrm{mg} \mathrm{L}^{-1} 2,4-\mathrm{D}+5 \mathrm{mg} \mathrm{L}^{-1} \mathrm{BAP}$ e $0,5 \mathrm{mg} \mathrm{L}^{-1} \mathrm{AIB}+5,0 \mathrm{mg} \mathrm{L}^{-1} \mathrm{BAP}$ suplementado com $2,4 \mathrm{~g} \mathrm{~L}^{-1}$ $\mathrm{NH}_{4} \mathrm{NO}_{3}$ em meio MS estimularam o crescimento dos calos. De maneira geral, os calos apresentaram aspectos friáveis, não embriogênicos, com acúmulo de fenóis e presença de áreas meristemáticas (meristemóides).
\end{abstract}

Palavras-chave: Pau-brasil, determinação, competência, calos, in vitro, nitrogênio, fitorreguladores

ABSTRACT - (Culture media, growth regulators and nitrogen sources in callus formation regulation of Brazilwood (Caesalpinia echinata Lam.)). The regulation of callus formation is the first step to indirect somatic embryogenesis in vitro. Therefore, we investigated hormonal and nutrient factors on development of callus in leaf tissues of Caesalpinia echinata (Brazilwood). Explants were cultivated in culture media MS, B5, WPM, and White. The effect of nitrogen sources $\left(\mathrm{NH}_{4} \mathrm{NO}_{3}, \mathrm{KNO}_{3}\right.$ and glutamine) and the interaction between auxins (2,4-D, IAA and IBA) and cytokinins (BAP and KIN) were also evaluated. Media MS, B5 and White were not significantly different and provided better results. MS medium containing $2.4 \mathrm{~g} \mathrm{~L}^{-1} \mathrm{NH}_{4} \mathrm{NO}_{3}, 1.35 \mathrm{~g} \mathrm{~L}^{-1}$ glutamine, and $4.11 \mathrm{~g} \mathrm{~L}^{-1}$ of $\mathrm{KNO}_{3}$ in the presence of $1 \mathrm{mg} \cdot \mathrm{L}^{-1}$ 2,4-D and $5 \mathrm{mg} . \mathrm{L}^{-1} \mathrm{BAP}$ increased cellular proliferation as determined by fresh weight of callus. The combination of plant growth regulators at $0.5 \mathrm{mg} \mathrm{L}^{-1} 2,4-\mathrm{D}+5.0 \mathrm{mg} \mathrm{L}^{-1} \mathrm{BAP}$ and $0.5 \mathrm{mg} \mathrm{L}^{-1} \mathrm{IBA}+5.0 \mathrm{mg} \mathrm{L}^{-1} \mathrm{BAP}$ supplemented with $2.4 \mathrm{~g}$ $\mathrm{L}^{-1} \mathrm{NH}_{4} \mathrm{NO}_{3}$ in MS medium stimulated growth of callus. In general, callus showed friable, non-embryogenic characteristics, with accumulation of phenolics and the presence of meristematic areas (meristems).

Key words: Brazilwood, determination, competence, callus, in vitro, nitrogen, growth regulators

\section{Introdução}

Uma das características mais notáveis das plantas está na capacidade de suas células somáticas desdiferenciar e retomar a divisão celular e produzir novas plantas. Entretanto, a alteração do programa ontogenético não é tão simples assim, pois nem todas as células adquirem competência para expressar a desdiferenciação celular. Dessa maneira, a caracterização fisiológica de tecidos e órgãos é fundamental para aplicação do princípio da desdiferenciação celular visando a organogênese ou a embriogênese somática in vitro (Lakshmanan \& Taji 2000; Gueye et al. 2009).

A alteração do programa ontogenético é regulada, especialmente, pela auxina exógena que, de acordo com sua concentração, pode favorecer determinada rota do desenvolvimento celular (Fehe'r et al. 2003; Gueye et al. 2009). Essa mudança do desenvolvimento celular passa por sucessivos processos (Christianson \& Warnick 1988; Sugiyema 1999). Numa primeira fase, denominada de aquisição de competência organogenética, ocorrem alterações citológicas em resposta aos sinais hormonais. Entende-se por competência celular a habilidade das células somáticas em expressar a capacidade da desdiferenciação celular (Verdeil et al. 2007). A fase seguinte é a de determinação em que o programa ce- lular é direcionado para um alvo morfogenético específico. A última fase é a da diferenciação em que as células expressam a morfogênese ou a calogênese.

Na rota da calogênese, são formados calos nodulares, que apresentam aspecto heterogêneo, e os calos friáveis que apresentam uma estrutura tenra composta de células com alta atividade mitótica (Besse et al. 1992). A semelhança entre esses tipos de calos está na origem. Tantos os calos nodulares quanto os friáveis podem ser formados da atividade das células do procâmbio (Buffard-Morel et al. 1992) ou da bainha perivascular (Gueye et al. 2009). Essas alterações no programa morfogenético são mais difíceis de serem controladas em espécies arbóreas em função da elevada presença de substâncias oxidativas (Preece 2008).

De fato, as arbóreas, com destaque às tropicais, são conhecidas pelos elevados níveis de fenóis inibitórios ao crescimento celular. Nas arbóreas tropicais, a fase de desenvolvimento dos explantes tem sido associada à concentração de fenóis. De modo geral, explantes mais jovens são menos propícios à oxidação in vitro (Preece 2008; Werner et al. 2009). Algumas medidas têm sido recomendadas para evitar a oxidação como a imersão dos explantes em soluções antioxidantes de ácido cítrico ou ácido ascórbico e adição de carvão ativado ao meio de cultura (Werner et al. 2009).

\footnotetext{
1 Universidade Federal do Espírito Santo, Departamento de Ciências Biológicas, Programa de Pós-Graduação em Biologia Vegetal, Vitória, ES, Brasil

2 University of Florida, Associate Professor, Tropical Research and Education Center, Homestead, FL, USA

Autor para correspondência: gcuzzuol@gmail.com
} 
Em relação aos reguladores de crescimento, a concentração e o balanço de auxinas e citocininas são fatores determinantes na diferenciação celular e no padrão de desenvolvimento in vitro (Junaid et al. 2007; Motoike et al. 2007; Gueye et al. 2009). As auxinas desencadeam os processos de desdiferenciação (modelo indireto) e rediferenciação (modelo direto) in vitro, alterando a determinação e conferindo novas competências às células responsivas dos explantes (Fehe'r et al. 2003). As citocininas estimulam a divisão celular e podem induzir a embriogênese somática (Mello et al. 2000).

Os meios de cultura mais utilizados são o MS desenvolvido por Murashige \& Skoog (1962), o WPM (Woody Plant Medium), formulado por Lloyd \& McCown (1981), o B5 estabelecido por Gamborg et al. (1968) e o White (White 1943). O componente-chave dos meios nutritivos é o nitrogênio, elemento associado ao controle do crescimento, diferenciação e morfogênese. Pode ser fornecido na forma de nitrato, amônio ou aminoácidos, dentre eles a glutamina. A combinação dessas fontes nitrogenadas tem proporcionado bons resultados na organogênese e morfogênese in vitro (Lakshmanan \& Taji 2000).

A compreensão dos processos fisiológicos que regulam a desdiferenciação celular é de grande interesse na conservação de espécies ameçadas de extinção como Caesalpinia echinata (pau-brasil), uma Fabaceae ocorrente na Mata Atlântica do Brasil. Para tanto, o conhecimento dos fatores que regulam o processo de desdiferenciação e rediferenciação celular é uma etapa fundamental na regeneração de plantas in vitro. O presente trabalho teve como objetivo principal definir as condições ideais para promover a expressão da desdiferenciação celular bem como avaliar o nível de competência e determinação dos tecidos foliares de C. echinata Lam. (pau-brasil), uma arbórea em extinção da Mata Atlântica.

\section{Material e métodos}

Material biológico - Foliólulos jovens na fase de desenvolvimento, conforme critério de Werner et al. (2009), foram coletados de folhas recompostas de plantas com 2 anos de idade de Caesalpinia echinata Lam. (Fabaceae) cultivadas em vasos de $8 \mathrm{~L}$ contendo solo e areia na proporção de $1: 1$, em casa de vegetação do Departamento de Ciências Biológicas da Universidade Federal do Espírito Santo em Vitória-ES $\left(20^{\circ} 19^{\prime} 09^{\prime \prime} \mathrm{S}, 40^{\circ} 20^{\prime} 50^{\prime \prime} \mathrm{W}\right)$. As condições ambientais naturais de cultivo das plantas foram fotoperído anual $12 \pm 1 \mathrm{~h}$, temperatura média anual $27 \pm 3{ }^{\circ} \mathrm{C}$ e $560 \mu \mathrm{mol} \mathrm{m} \mathrm{m}^{-1}$ de radiação fotossinteticamente ativa (30\% de radiação solar) determinada às 12:00 horas de um dia ensolarado sem nuvens em um auantometro da Spectrum Technologies, Inc. Mod 3415F, USA. Os foliólulos foram acondicionados em frascos Erlenmeyer contendo água destilada esterilizada e no laboratório foram lavados com detergente neutro comercial em água corrente durante 10 minutos para pré-limpeza e imersos em álcool etílico $70 \%$ por 1 minuto, seguido de imersão em solução contendo hipoclorito de sódio $0.2-4 \%$ de cloro ativo, durante 20 minutos, em constante agitação, seguido de três enxágües de água destilada estéril. Em seguida foram retirados discos de $0.7 \mathrm{~cm}$ de diâmetro na região da nervura central que após lavagem em solução antioxidante contendo $150 \mathrm{mg} \mathrm{L}^{-1}$ de ácido cítrico por 15 minutos em agitação no escuro, foram transferidos para meio de cultura MS (Murashige \& Skoog 1962) confome protocolo estabelecido por Wernet et al. (2009) para indução da calogênese. Essa etapa visou a produção de calos para as análises de reguladores de crescimento e fontes nitrogenadas na regulação da desdiferenciação celular. Previamente, foi analisado o efeito de diferentes meios de cultura na formação de calos para definir o melhor meio para os testes com reguladores de crescimento e fontes nitrogenadas. Meios de cultura - Discos de foliólulos na fase jovem de desenvolvimento foram inoculados nos meios de cultura MS, B5, White e WPM suplementados com $20 \mathrm{mg} \mathrm{L}^{-1}$ de 2,4-D (2,4-diclorofenoxiacético) e 5,0 $\mathrm{mg} \mathrm{L}^{-1}$ de BAP (benzilaminopurina). Após 60 dias de cultivo, os calos formados foram isolados e transferidos para os meios de cultura MS, B5 White e WPM livres de fitorreguladores, $\mathrm{pH}$ 5,8, $30 \mathrm{~g} \mathrm{~L}^{-1}$ sacarose e 7,5 $\mathrm{g} \mathrm{L}^{-1}$ de ágar.

Fontes de nitrogênio - $\mathrm{O}$ meio utilizado foi o $\mathrm{MS}$, conforme resultado obtido no experimento anterior, modificando-se apenas as fontes de nitrogênio. A concentração de cada fonte foi ajustada de tal forma que a quantidade de nitrogênio fosse a mesma em cada tratamento $\left(0,84 \mathrm{mg} \mathrm{L}^{-1}\right)$, tendo como base a concentração de nitrogênio do meio MS. Segmentos dos calos $(0,5 \mathrm{~g} \pm 0,01$ de massa fresca) cultivados por 60 dias em meio MS contendo $20 \mathrm{mg} \mathrm{L}^{-1} 2,4-\mathrm{D}$ (2,4 diclorofenoxiacético) foram submetidos aos tratamentos T1: $\mathrm{NH}_{4} \mathrm{NO}_{3}\left(2,4 \mathrm{~g} \mathrm{~L}^{-1}\right)$; $\mathrm{T} 2: \mathrm{KNO}_{3}\left(6,06 \mathrm{~g} \mathrm{~L}^{-1}\right)$; T3: glutamina $(4,39$ $\left.\mathrm{g} \mathrm{L}^{-1}\right)$; $\mathrm{T} 4: \mathrm{NH}_{4} \mathrm{NO}_{3}\left(1,65 \mathrm{~g} \mathrm{~L}^{-1}\right)+\mathrm{KNO}_{3}\left(1,9 \mathrm{~g} \mathrm{~L}^{-1}\right)$; T5: glutamina $(1,35$ $\left.\mathrm{g} \mathrm{L}^{-1}\right)+\mathrm{NH}_{4} \mathrm{NO}_{3}\left(1,65 \mathrm{~g} \mathrm{~L}^{-1}\right)$; T6: glutamina $\left(1,35 \mathrm{~g} \mathrm{~L}^{-1}\right)+\mathrm{KNO}_{3}(4,11 \mathrm{~g}$ $\left.\mathrm{L}^{-1}\right)$; T7: glutamina $\left(1,02 \mathrm{~g} \mathrm{~L}^{-1}\right)+\mathrm{KNO}_{3}\left(1,4 \mathrm{~g} \mathrm{~L}^{-1}\right)+\mathrm{NH}_{4} \mathrm{NO}_{3}\left(1,2 \mathrm{~g} \mathrm{~L}^{-1}\right)$. Aos tratamentos, foram acrescentados $1,0 \mathrm{mg} \mathrm{L}^{-1} 2,4-\mathrm{D}$ e $5,0 \mathrm{mg} \mathrm{L}^{-1} \mathrm{BAP}$. Aos 60 dias após a inoculação determinou-se a massa seca, após secagem por $48 \mathrm{~h}$ em estufa a $60^{\circ} \mathrm{C}$.

Reguladores de crescimento - Segmentos de calos $(0,5 \mathrm{~g} \pm 0,01$ de massa fresca) cultivados por 60 dias em meio MS suplementado com $20 \mathrm{mg} \mathrm{L}^{-1}$ 2,4-D foram pesados em balança digital esterelizada em câmara de fluxo laminar e transferidos para novos meios de cultura MS suplementados com 2,4-D, BAP, AIB (ácido indolbutírico) e KIN (cinetina) combinados da seguinte forma: tratamento T1: $0,5 \mathrm{mg} \mathrm{L}^{-1} 2,4-\mathrm{D}+5,0 \mathrm{mg} \mathrm{L}^{-1} \mathrm{BAP} ; \mathrm{T} 2: 0,5$ $\mathrm{mg} \mathrm{L}^{-1}$ 2,4-D + 5,0 $\mathrm{mg} \mathrm{L}^{-1} \mathrm{KIN}$; T3: 0,5 $\mathrm{mg} \mathrm{L}^{-1} \mathrm{AIB}+5,0 \mathrm{mg} \mathrm{L}^{-1} \mathrm{BAP}$; 4 : $0,5 \mathrm{mg} \mathrm{L}^{-1} \mathrm{AIB}+5,0 \mathrm{mg} \mathrm{L}^{-1} \mathrm{KIN}$; T5: 0,5 mg L-1 AIA + 5,0 $\mathrm{mg} \mathrm{L}^{-1} \mathrm{BAP}$; T6: $0,5 \mathrm{mg} \mathrm{L}^{-1} \mathrm{AIA}+5,0 \mathrm{mg} \mathrm{L}^{-1} \mathrm{KIN}$. O meio de cultura foi modificado contendo $2,4 \mathrm{~g} \mathrm{~L}^{-1} \mathrm{NH}_{4} \mathrm{NO}_{3}$ como fonte de nitrogênio conforme resultados do experimento anterior. Aos 60 dias após a inoculação determinou-se a massa seca, após secagem por $48 \mathrm{~h}$ em estufa a $60{ }^{\circ} \mathrm{C}$.

Análise histológica - Calos com 60 dias de inoculação e produzidos nos diferentes tratamentos foram fixados em FAA 50 (Johansen, 1940), desidratados em série etílica crescente $(50,60,70,90,95$ e 100\%) e incluídos em resina glicol-metacrilato (Leica Historesin $®$ ). Os blocos foram cortados transversalmente e longitudinalmente (10 $\mu \mathrm{m}$ de espessura) em micrótomo rotativo, com a utilização de navalhas de aço. Os cortes foram corados com Azul de Toluidina (O’Brien 1964) e as lâminas histológicas foram montadas em resina sintética Entellan. As observações e a documentação fotográfica foram realizadas utilizando um fotomicroscópio Nikon.

Análise estatística - O delineamento experimental foi em blocos casualizados sendo que cada parcela foi constituída por quatro placas de Petri contendo cinco explantes $(n=4)$. Os valores de massa seca foram submetidos à análise de variância utilizando-se o software ASSISTAT. Para a comparação das médias foi realizado o teste de Duncan no nível de $5 \%$ de probabilidade.

\section{Resultados e discussão}

Os meios de cultura White, MS, B5 proporcionaram melhores resultados no resgate da capacidade de divisão celular indicada pela porcentagem de calos formados (Tab. 1). Embora, o meio WPM seja bastante utilizado na promoção da calogênese e da organogênese de espécies lenhosas (Glocke et al. 2006), no presente trabalho este meio não foi eficiente, provavelmente por apresentar $50 \%$ da força iônica dos meios MS, White e B5 bem como elevado nível de $\mathrm{S}$ e baixos níveis de $\mathrm{NH}_{4}^{+}$e $\mathrm{NO}_{3}^{-}$. De qualquer modo, a comparação de diferentes meios de cultura é uma tarefa complexa devido às interações entre os nutrientes minerais, o potencial osmótico do meio e as exigências nutricionais de cada planta. 
1048 Werner et al: : Meios de cultura, reguladores de crescimento e fontes de nitrogênio na regulação da calogênese do pau-brasil...

Tabela 1. Massa seca de calos (mg) de C. echinata após 60 dias de cultivo em meios de cultura, White, MS, B5 e WPM suplementado com 1,0 mg L $\mathrm{L}^{-1}$ de 2,4-D e $5,0 \mathrm{mg} \mathrm{L}^{-1}$ de BAP. Médias seguidas por letras iguais não diferem entre si, a $5 \%$ de probabilidade, pelo teste Duncan. \pm representa o desvio padrão de $n=10$.

\begin{tabular}{ll}
\hline Meio de cultura & Massa seca de calos $(\mathrm{mg})$ \\
\hline White & $62,78 \pm 5,7 \mathrm{a}$ \\
MS & $53,54 \pm 5,2 \mathrm{ab}$ \\
B5 & $42,96 \pm 6,3 \mathrm{~b}$ \\
WPM & $22,28 \pm 3,8 \mathrm{c}$ \\
\hline
\end{tabular}

Os resultados referentes às fontes de nitrogênio testadas isoladamente e combinadas são apresentadas na Tab. 2. As fontes $\mathrm{NH}_{4} \mathrm{NO}_{3}$ e glutamina $+\mathrm{KNO}_{3}$ foram as mais eficazes na promoção da divisão celular indicada pela massa seca dos calos. A utilização isolada de $\mathrm{KNO}_{3}$ e glutamina bem como a combinação de $\mathrm{NH}_{4} \mathrm{NO}_{3}+\mathrm{KNO}_{3}$, glutamina $+\mathrm{NH}_{4} \mathrm{NO}_{3}$ e glutamina $+\mathrm{NH}_{4} \mathrm{NO}_{3}+\mathrm{KNO}_{3}$ não foram tão eficientes quanto o $\mathrm{NH}_{4} \mathrm{NO}_{3}$ e a combinação de glutamina $+\mathrm{KNO}_{3}$ para a proliferação celular dos calos. Embora $\mathrm{KNO}_{3}$ seja a fonte de nitrogênio mais utilizada em meios de cultura, muitas espécies incorporam nitrogênio e crescem mais rapidamente em soluções contendo $\mathrm{NH}_{4} \mathrm{NO}_{3}$ do que na presença de íons $\mathrm{NH}_{4}$ e $\mathrm{NO}_{3}$ ofertados separadamente (George \& De Klerk 2008) como constatados em calos do pau-brasil (Tab. 2).

Além de fontes inorgânicas, o nitrogênio na forma orgânica como a glutamina acrescentada isoladamente e associada com $\mathrm{NH}_{4} \mathrm{NO}_{3}$ também foi insatisfatória no crescimento dos calos (Tab. 2). Em alguns casos, a glutamina pode provocar a morte celular (George \& de Klerk 2008), indicando que para determinadas culturas, as fontes orgânicas de nitrogênio não são eficientes. A inibição do crescimento dos calos de pau-brasil em meio contendo $\mathrm{KNO}_{3}$ e glutamina $+\mathrm{NH}_{4} \mathrm{NO}_{3}$ não foi provocada por diferenças nos níveis de nitrogênio uma vez que as concentrações de $\mathrm{N}$ foram semelhantes para todos os meios ustilizados $\left(0,84 \mathrm{~g} \mathrm{~L}^{-1}\right)$. Dessa forma, o baixo crescimento dos calos do pau-brasil na presença de $\mathrm{KNO}_{3}$ e glutamina $+\mathrm{NH}_{4} \mathrm{NO}_{3}$ pode ser devido à dificuldade das células em absorver e/ou metabolizar essas fontes nitrogenadas.

As combinações das concentrações dos reguladores de crescimento $0,5 \mathrm{mg} \mathrm{L}^{-1} 2,4-\mathrm{D}+5,5 \mathrm{mg} \mathrm{L}^{-1}$ BAP e $0,5 \mathrm{mg} \mathrm{L}^{-1}$ $\mathrm{AIB}+5,5 \mathrm{mg} \mathrm{L}^{-1} \mathrm{BAP}$ estimularam a proliferação celular indicada pela massa seca dos calos (Tab. 3). O melhor crescimento de calos em meio suplementado com auxinas, especialmente o 2,4-D associada à citocinina BAP, tem proporcionado resultados satisfatórios na organogênese e embriogênese somática in vitro (Bonfill et al. 2002). Os tratamentos com AIA não foram tão eficientes na promossão do crescimento dos calos quando comparados com os reguladores 2,4-D e AIB (Tab. 3) e isso pode ter ocorrido devido a instabilidade das auxinas causada pela fotoxidação ou pela ação do complexo de enzimas oxidativas (Geisler et al. 2005). A expressão da desdiferenciação celular pode ser independente de auxinas e citocininas, dependente de auxinas, dependente de citocininas ou dependente de ambas (Preece 2008). Para C. echinata, a desdiferenciação celular, indicada pela capacidade dos tecidos em formar calos, é dependente da concentração de auxina e

Tabela 2. Massa seca de calos (mg) de C. echinata após 60 dias de cultivo em meio MS suplementado com 1,0 mg L $\mathrm{m}^{-1} 2,4-\mathrm{D}$ e 5,0 mg L $\mathrm{m}^{-1} \mathrm{BAP}$ em diferentes fontes inorgânicas e orgânicas de nitrogênio. Médias seguidas por letras iguais não diferem entre si, a 5\% de probabilidade, pelo teste Duncan. \pm representa o desvio padrão de $n=10$.

\begin{tabular}{lc}
\hline Fontes nitrogenadas & Massa seca de calos (mg) \\
\hline $2,40 \mathrm{~g} \mathrm{~L}^{-1} \mathrm{NH}_{4} \mathrm{NO}_{3}$ & $54,86 \pm 4,5 \mathrm{a}$ \\
$1,35 \mathrm{~g} \mathrm{~L}^{-1} \mathrm{GLUTAMINA}+4,11 \mathrm{~g} \mathrm{~L}^{-1} \mathrm{KNO}_{3}$ & $43,90 \pm 4,6 \mathrm{~b}$ \\
$1,02 \mathrm{~g} \mathrm{~L}^{-1} \mathrm{GLUTAMINA}+1,4 \mathrm{~g} \mathrm{~L}^{-1} \mathrm{NH}_{4} \mathrm{NO}_{3}+1.2 \mathrm{~g} \mathrm{~L}^{-1} \mathrm{KNO}_{3}$ & $32,10 \pm 4,2 \mathrm{c}$ \\
$4,39 \mathrm{~g} \mathrm{~L}^{-1} \mathrm{GLUTAMINA}$ & $27,88 \pm 3,8 \mathrm{c}$ \\
$1,65 \mathrm{~g} \mathrm{~L}^{-1} \mathrm{NH}_{4} \mathrm{NO}_{3}+1,9 \mathrm{~g} \mathrm{~L}^{-1} \mathrm{KNO}_{3}$ & $25,28 \pm 2,9 \mathrm{c}$ \\
$6,06 \mathrm{~g} \mathrm{~L}^{-1} \mathrm{KNO}_{3}$ & $19,02 \pm 3,2 \mathrm{~d}$ \\
$1,35 \mathrm{~g} \mathrm{~L}^{-1} \mathrm{GLUTAMINA}+1,65 \mathrm{~g} \mathrm{~L}^{-1} \mathrm{NH}_{4} \mathrm{NO}_{3}$ & $18,22 \pm 1,8 \mathrm{~d}$ \\
\hline
\end{tabular}

Tabela 3. Massa seca de calos (mg) de C. echinata após 60 dias de cultivo em meio MS suplementado com $2,4 \mathrm{~g} \mathrm{~L}^{-1} \mathrm{de} \mathrm{NH}_{4} \mathrm{NO}_{3}$ em diferentes interações entre auxinas e citocininas. Médias seguidas por letras iguais não diferem entre si, a $5 \%$ de probabilidade, pelo teste Duncan. \pm representa o desvio padrão de $n=10$.

\begin{tabular}{ll}
\hline Reguladores de crescimento & Massa seca de calos (mg) \\
\hline $0,5 \mathrm{mg} \mathrm{L}^{-1} 2,4-\mathrm{D}+5,5 \mathrm{mg} \mathrm{L}^{-1} \mathrm{BAP}$ & $16,18 \pm 2,6 \mathrm{a}$ \\
$0,5 \mathrm{mg} \mathrm{L}-1 \mathrm{AIB}+5,5 \mathrm{mg} \mathrm{L}^{-1} \mathrm{BAP}$ & $14,00 \pm 1,9 \mathrm{a}$ \\
$0,5 \mathrm{mg} \mathrm{L}^{-1} \mathrm{AIA}+5,5 \mathrm{mg} \mathrm{L}^{-1} \mathrm{BAP}$ & $10,43 \pm 1,6 \mathrm{~b}$ \\
$0,5 \mathrm{mg} \mathrm{L}^{-1} 2,4-\mathrm{D}+5,5 \mathrm{mg} \mathrm{L}^{-1} \mathrm{KIN}$ & $09,95 \pm 2,2 \mathrm{~b}$ \\
$0,5 \mathrm{mg} \mathrm{L}^{-1} \mathrm{AIA}+5,5 \mathrm{mg} \mathrm{L}^{-1} \mathrm{KIN}$ & $09,95 \pm 2,8 \mathrm{~b}$ \\
$0,5 \mathrm{mg} \mathrm{L}^{-1} \mathrm{AIB}+5,5 \mathrm{mg} \mathrm{L}^{-1} \mathrm{KIN}$ & $09,27 \pm 2,3 \mathrm{~b}$ \\
\hline
\end{tabular}


pode estar relacionada com a fase de desenvolvimento dos foliólulos conforme apontaram Werner et al. (2009). Esses autores levantaram a hipótese de que foliólulos de pau-brasil na fase juvenil do desenvolvimento possuem características morfológicas e fisiológicas ideais para a expressão da desdiferenciação celular. Dentre esses aspectos, maiores níveis de auxinas endógenas e presença de epiderme e cutícula delgada na juvenilidade podem facilitar a absorção de nutrientes, vitaminas, açúcares e reguladores do crescimento (Fouda 1996, Taiz \& Zaiger 2004). Tais informações sugerem que a utilização de foliólulos juvenis ao invés de jovens como adotado no presente trabalho poderiam ter proporcionado resultados differentes e, portanto deveriam ser estudados em trabalhos futuros. No entanto, a baixa produção de foliólulos juvenis verificada nas plantas matrizes (dados não apresentados) inviabilizaria a execução dos experimentos no presente trabalho.

Fatores ambientais também interferem nas respostas morfogenéticas. O foliólulos de pau-brasil apresentam substâncias oxidativas como os fenóis (Mengarda 2010) inibitórias à divisão e crescimento celular (Preece 2008). Tais características químicas dos foliólulos podem ter bloqueado a expressão da determinação celular para as rotas morfogéneticas desejáveis como à formação de embriões somáticos e/ou gemas adventícias.

A calogênese ocorreu na superfície adaxial dos foliólulos (Fig. 1A,B), resultado da proliferação das células do parênquima. Em todos os tratamentos, os calos apresentaram coloração variando do amarelo escuro a marrom (Fig. 1C). De modo geral, calos compactos e de coloração translúcida são mais suscetíveis a embriogênese ou organogênese (Chaudhury \& Qu 2000). Os calos apresentaram-se com aspecto não embriogênico constituídos por células alongadas, altamente vacuolizadas, com acúmulo de compostos fenólicos e com espaços entre si (Fig. 1E). Células pequenas, isodiamétricas e de arranjo compacto podem ser observadas na zona central (Fig. 1D). Notam-se grupos de células em intensa divisão, constituindo áreas meristemáticas (meristemóides) formadas por células pequenas, isodiamétricas, com
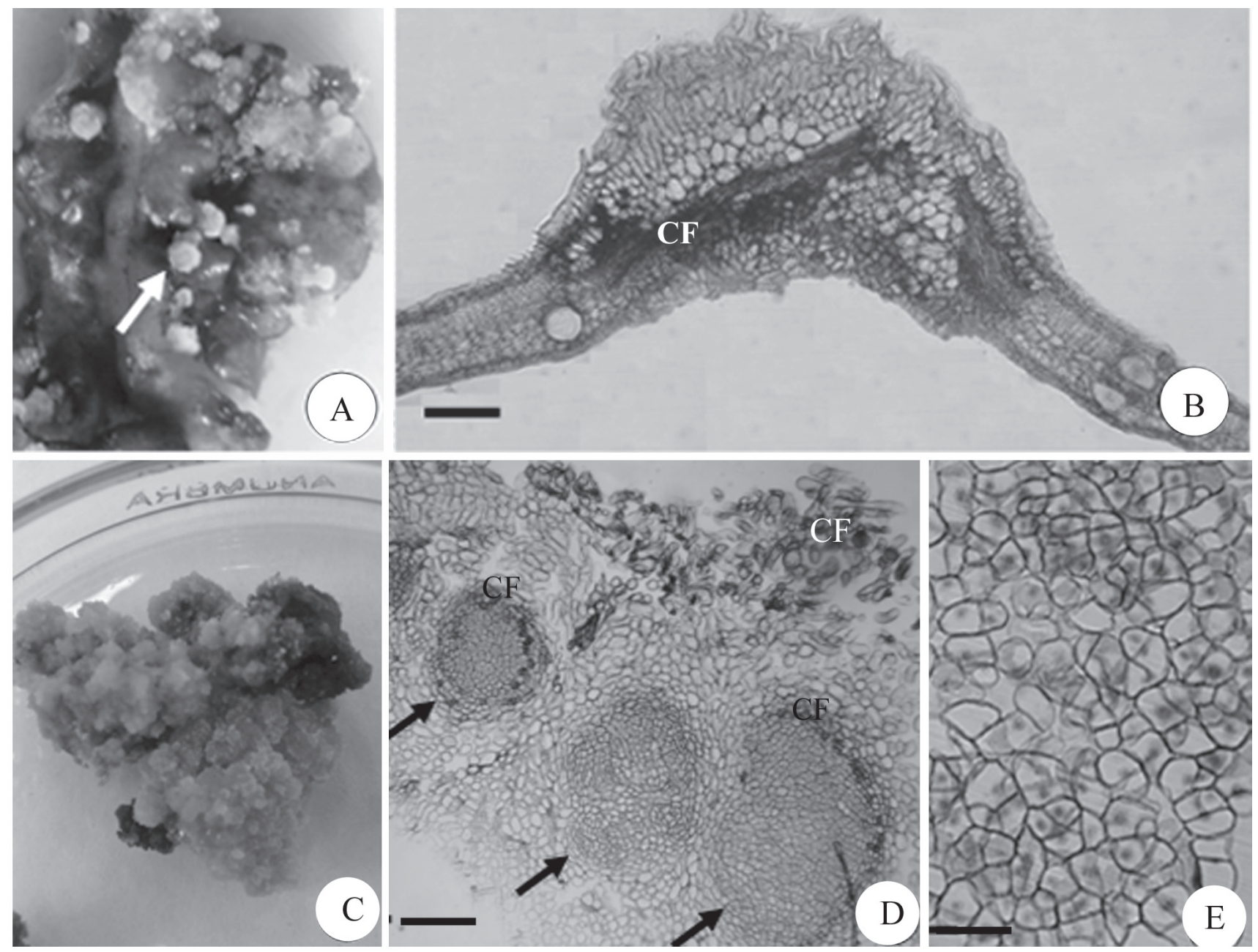

Figura 1. Aspectos morfológicos e histológicos dos calos de C. echinata cultivados in vitro. A-B. Após 30 dias de inoculação. A. Formação de calos (seta) no foliólulo. B. Secção transversal do limbo mostrando formação de calo na face adaxial do foliólulo e conteúdo de fenóis (CF). C-E. Após 60 dias de inoculação. C. Aspecto geral do calo. D-E. Secções transversais. D. Meristemóides (setas) e células com conteúdo fenólico (CF). E. Detalhe de células em divisão mostrando núcleo conspícuo. Barra $=100 \mu \mathrm{m}(\mathrm{B}), 200 \mu \mathrm{m}$ (D), $50 \mu \mathrm{m}$ (E). 
citoplasma denso e núcleo conspícuo (Fig. 1F). De maneira geral, os calos de pau-brasil mostraram a ocorrência de um setor central com células alongadas e de arranjo frouxo e outro com células pequenas e isodiamétricas, levando a formação de meristemóides como constatados em outras espécies (Mello et al. 2000; Lombardi et al. 2007). De acordo com Fehe'r et al. (2003), a formação de uma área meristemática, e finalmente, um órgão, está relacionada à capacidade de uma célula em responder a sinais específicos, provavelmente de natureza hormonal.

O acúmulo de compostos fenólicos nos calos de paubrasil foi expressivo (Fig 1E). Segundo Preece et al. (2008) a ação oxidativa de compostos fenólicos constitui um fator limitante no crescimento das culturas in vitro. Embora, não tenha sido realizada análise quantitativa de fenóis nos calos de pau-brasil, os resultados sugerem que o acúmulo destes compostos seja um dos fatores limitantes da determinação celular para uma rota morfogenética específica.

No entanto, Werner et al. (2009) discutem que a falta de formação de embriões somáticos ou a falta de sinais de expressão para outro alvo morfogenético não significa que necessariamente as células dos calos do pau-brasil não tenham entrado na fase de determinação celular. Nem sempre, a divisão celular resulta diretamente em um embrião, mas sim em massas pró-embriogênicas (MPEs) as quais apenas algumas irão se desenvolver em embriões (Myers 2004). Vestígios de MPEs foram identificadas por Werner et al. (2009) em calos de pau-brasil independente das concentrações e balanço dos reguladores auxinas e citocininas. Esses autores relatam que as MPEs não se transformaram em embriões somáticos. Tais informações sugerem que o mecanismo de diferenciação celular para determinadas espécies pode ser controlado por outras condições como o balanço entre os reguladores de crescimento ou reduzindo as concentrações de nutrientes (Lakshmanan \& Taji 2000). No entanto, mesmo seguindo essas considerações não se constatou, no presente trabalho, estruturas que pudessem ser associadas à embriões somáticos, gemas adventícias ou raízes, mostrando que a expressão da determinação celular em pau-brasil seja um mecanismo bastante complexo dada as suas características fisiológicas específicas.

A presença de várias áreas meristemáticas (meristemóides) sugere que os tecidos foliares do pau-brasil possuem certa competência, mas alguns fatores endógenos como os fenóis possam estar impedindo o processo da diferenciação celular para a rota da embriogênese somática ou na formação de gemas adventícias. Entre as Fabaceae lenhosas, a formação de embriões somáticos não é um processo comum (Kumar et al. 2002) assim como verificado em C. echinata. Contudo, o presente estudo mostrou que os tecidos dessa arbórea tropical do Brasil são competentes para a expressão da desdiferenciação celular e de que o processo da determinação celular esteja sob controle de fatores endógenos como elevados níveis de fenóis. Com isso, os resultados obtidos reforçam a necessidade de novos estudos relacionados ao controle de síntese de fenóis visando à expressão da determinação via organogênese ou embriogênese somática visando a conservação do pau-brasil in vitro.

\section{Agradecimentos}

À Fundação Biodiversitas, à Fundação de Apoio à Pesquisa do Espírito Santo-FAPES (Processo 39044823/2007) e ao Fundo de Apoio Científico e Tecnológico da Prefeitura Municipal de Vitória-FACITEC (Processo 38/2007) pelo apoio financeiro.

\section{Referências bibliográficas}

Besse, I.; Verdeil, J.L.; Duval, Y.; Sotta, B.; Maldiney, R.; Miginiac, R. \& Migininac, E. 1992. Oil palm (Elaeis guineensis Jacq.) clonal fidelity: endogenous cytokinins and indolacetic acid in embryogenic callus cultures. Journal of Experimental Botany 43: 983-989.

Bonfill, M.; Cusidó, R.M.; Palazón, J.; Piñol, M.T. \& Morales, C. 2002. Influence of auxins on organogenesis and ginsenoside production in Panax ginseng calluses. Plant Cell, Tissue and Organ Culture 68: 73-78.

Buffard-Morel, J.; Verdeil, J.L \& Pannetier, C. 1992. Embryogene'se somatique du cocotier (Cocos nucifera L.) a' partir d'explant foliaire: e'tude histologique. Canadian Journal of Botany 70: 735-741.

Chaudhury, A. \& QU, R. 2000. Somatic embryogenesis and plant regeneration of turf-type bermudagrass: Effect of 6-benzyladenine in callus induction medium. Plant Cell, Tissue and Organ Culture 60(2): 113-120.

Christianson, M.I, Warnick, D.A. 1988. Organogenesis in vitro as developmental process. HortScience 23: 515-519.

Fehe'r, A.; Pasternak, T.P. \& Dudits, D. 2003. Transition of somatic plant cells to an embryogenic state. Plant Cell, Tissue and Organ Culture 74: 201-228.

Fouda, R.A. 1996. Anatomical characteristics of juvenile and adult shoots associated with rooting ability of Cupressocyparis leylandii cuttings. Horticultural Science 28: 107-111.

Gamborg, O.L.; Miller, R.A. \& Ojima, K. 1968. Nutrient requirements of suspension cultures of soybean root cells. Experimental Cell Research 50: 151-158.

Geisler, M.; Blakeslee, J.J.; Bouchard, R.; Lee, O.R.; Vincenzetti, V.; Bandyopadhyay, A.; Peer, W.A.; Bailly, A.; Richards, E.L. \& Ejendal, K.F.K. 2005. Cellular efflux of auxin mediated by the Arabidopsis MDR/PGP transporter At PGPI. Plant Journal 44: 179-194.

George, E.F. \& De Klerk, G.J. 2008. The components of plant tissue culture media I: macro- and micro-nutrients. Pp. 355-402. In: George, E.F.; Hall, M.A \& Klerk, G. De (orgs.). Plant Propagation by Tissue Culture. 3 ed. Dordrecht, Springer.

Glocke, P.; Delaporte, K.; Collins, G. \& Sedgley, M. 2006. Micropropagation of juvenile tissue of Eucalyptus erythronema $\mathrm{x}$ Eucalyptus stricklandii Cv. 'Urrbae Gem'. In Vitro Cellular and Developmental Biology Plant 42: 139-143.

Gray, D.J. 2000. Nonzygotic embryogenesis. Pp. 175-189. In: Trigiano, R.N. \& Gray, D.J (orgs.). Plant Tissue Culture Concepts and Laboratory Exercises. Boca Raton, CRC Press.

Gueye, B.; Saïd-Ahmed, H.; Morcillo, F.; Borgel, A.; Sané, D., Hilbert, J.L.; Verdeil, J.L. \& Blervacq, A.S. 2009. Callogenesis and rhizogenesis in date palm leaf segments: are there similarities between the two auxininduced pathways? Plant Cell, Tissue and Organ Culture 98: 47-58.

Hall, R.M.; Drew, R.A.; Higgins, C.M. \& Dietzgen, R.G. 2000. Efficient organogesis on Australian passionfruit hybrid (Passiflora edulis $\mathrm{x}$ Passiflora edulis var. flavicarpa) suitable for gene delivery. Australian Journal of Botany 48: 673-680.

Ipekci, Z. \& Gouzukirmizi, N. 2005. Indirect somatic embryogenesis and plant regeneration from leaf and internode explants of Paulownia elongata. Plant Cell, Tissue and Organ Culture 79: 341-345.

Junaid, A.; Mujib, A.; Bhat, M.A. \& Sharma, M.P. 2006. Somatic embryo proliferation, maturation and germination in Catharanthus roseus. Plant Cell, Tissue and Organ Culture 84: 325-332. 
Junaid, A.; Mujib, A.; Sharma, M.P. \& Tang, W. 2007. Growth regulators affect primary and secondary somatic embryogenesis in Madagaskar periwinkle (Catharanthus roseus (L.) G. Don) at morphological and biochemical levels. Plant Growth Regulation 51: 271-281.

Kumar, S.; Agrawal, V. \& Gupta, S.C. 2002. Somatic embryogenesis in the woody legume Calliandra tweedii. Plant Cell, Tissue and Organ Culture 71: 77-80.

Lakshmanan, P. \& Taji, A. 2000. Somatic embryogenesis in leguminous plants. Plant Biology 2: 136-148.

Lloyd, G. \& Mccown, B. 1981. Commercially-feasible micropropagation of Mountain laurel, Kalmia latifolia, by use of shoot tip culture. International Plant Propagation Society Proceedings 30: 421-427.

Lombardi, S.P.; Passos, I.R.S.; Nogueira, M.C.S. \& Appezato-da-Glória, B. 2007. In vitro shoot regeneration from roots and leaf discs of Passiflora cincinnata Mast. Brazilian Archives of Biology and Technology 50(2): 239-247.

Ljung, K.; Bhalerao, R.P. \& Sandberg, G. 2001. Sites and homeostatic control of auxin biosynthesis in Arabidopsis during vegetative growth. Plant Journal 28(4): 465-474.

Mello, M.O. \& Appezzato-da-Glória, B. 2000. Bauhinia forficata link shoot regeneration: histological analysis of organogenesis pathway. Brazilian Archives of Biology and Technology 43(4): 0-0.

Mengarda, L.G.H. 2010. Respostas morfofisiológicas do pau-brasil (Caesalpinia echinata Lam.) à radiação solar. Dissertação de Mestrado. Vitória, Universidade Federal do Espírito Santo.

Motoike, S.Y.; Saraiva, E.S.; Ventrella, M.C.; Silva, C.V. \& Salomão, L.C.C. 2007. Somatic embryogenesis of Myrciaria aureana (Brazilian grape tree). Plant Cell, Tissue and Organ Culture 89: 75-81.
Murashige, T. \& Skoog, F.A. 1962. A revised medium for rapid growth and bioassays with tabaco tissue cultures. Physiologia Plantarum 15(3): 473-497.

Myers, A. 2004. Somatic embryogenesis induction in Delonix regia (Boger.) (Royal Poinciana). Journal of Undergraduate Research 5(6) March. Disponível em: <http://www.clas.ufl.edu/jur/200403/ papers/paper_myers.html $>$.

O'Brien, T.P.; Feder, N. \& McCully, M. E. 1964. Polychromatic staining of plant cell walls by Toluidine blue O. Protoplasma 59: 368-373.

Preece, J. 2008. Plant physiological factors affecting growth and morphogenesis. Pp. 403-422. In: George, E.F.; Hall, M.A.; \& De Klerk, G. (orgs.). Plant Propagation by Tissue Culture. Dordrecht, Springer, 3rd Edition.

Sugiyama, M. 1999. Organogenesis in vitro. Current Opinion in Plant Biology 2: 61-64.

Teixeira, J.B.; Söndahl, M.R. \& Kirby, E.G. 1993. Somatic embryogenesis from immature zygotic embryos of oil palm. Plant Cell, Tissue and Organ Culture 34: 227-233.

Thomas, P. \& Ravindra, M.B. 1997. Shoot tip culture in mango: influence of medium, genotype, explant factors, season and decontamination treatments on phenolic exudation, explant survival and axemic culture establishment. Journal of Horticulturte Science 72(5): 713-722.

Werner, E.T.; Pessotti, K.V.; Lopes, F.P; Roger, J.A. \& Cuzzuol, G.R.F. 2009. Controle da calogênese do pau-brasil in vitro. Revista Árvore 33: $987-996$.

White, P.R. 1943. A handbook of plant tissue culture. Lancaster, Jaques Cattell Press.

Zimmerman, J.L. 1993. Somatic embryogenesis: a model for early development in higher plants. Plant Cell 5: 1411-1423.

Versão eletrônica do artigo em www.scielo.br/abb e http://www.botanica.org.br/acta/ojs 